\title{
Diffuse large b-cell lymphoma with hemophagocytic syndrome in an HIV+ patient treated with CCR5- bone marrow transplant
}

Elena Vrotsos ${ }^{1 *}$, Crystal Rego $^{2}$, Mike Cusnir $^{3}$, Claudio Tuda ${ }^{2}$ and Vathany Sriganeshan ${ }^{1}$

*Correspondence: Elena.Vrotsos@hhchealth.org

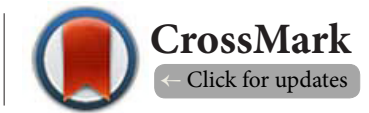

\author{
'Mount Sinai Medical Center, Department of Pathology and Laboratory Medicine, Miami Beach, Florida, USA. \\ Department of Internal Medicine, Miami Beach, Florida, USA. \\ ${ }^{3}$ Department of Hematology and Oncology, Miami Beach, Florida, USA.
}

\begin{abstract}
Hemophagocytic lymphohistiocytosis (HLH) is a life threatening systemic disease characterized by proliferation of activated lymphocytes/macrophages leading to an exaggerated but ineffective immune response. HLH clinically presents with fever, pancytopenia, splenomegaly and hemophagocytosis in the bone marrow, lymph nodes or liver. HLH has been associated with viral, bacterial, fungal, parasitic infections, and malignancies, particularly T-cell lymphomas, and collagen-associated vascular diseases. We describe a case of an HIV positive patient who presented to the emergency department with fever, cough, diarrhea and abdominal pain. A CT scan revealed diffuse lymphadenopathy. Excisional biopsy of the lymph node showed almost complete effacement of the normal lymph node architecture. The effaced areas were composed of small lymphocytes, medium size cells with features of centroblasts, several immunoblasts and ReedSternberg like cells. Increased number of histiocytes with hemophagocytosis was also observed. Diagnosis of EBV positive diffuse large B cell lymphoma was made. In addition, clinical presentation, laboratory results and morphology led to the diagnosis of HLH. This is a unique case describing a well-controlled HIV positive patient who developed HLH triggered by reactivation of EBV with diffuse large B cell lymphoma. The patient underwent allogeneic homozygous CCR5-transplant with a possibility of curing his large B cell lymphoma and HIV. He is currently under surveillance for his HIV status and lymphoma.
\end{abstract}

Keywords: DLBCL, CCR5-transplant, HIV+, EBV+, HLH

\section{Introduction}

$\mathrm{HLH}$ is a rare and potentially fatal hyperinflammatory condition caused by a hyperactivated but ineffective immune response. It was first described by Scott and Robb-Smith in 1939 [1]. The incidence of $\mathrm{HLH}$ is estimated to be approximately 1.2 cases per million per year, but this may be due to underrecognition and underreporting of the cases [2]. HLH can be classified into two forms. A primary or familial form occurs in infancy and is an autosomal recessive disorder associated with an underlying genetic mutation. A more common secondary form of HLH can occur in children and adults and is associated with a variety of triggers like infections, neoplasia and autoimmune conditions. Our patient had multiple factors that led to the development of HLH.

\section{Case report}

We present a case of a 52-year-old white man with a medical history of HIV (diagnosed in 1992) with a last known CD4 count of 600 cells $/ \mathrm{mm}^{3}$ and undetectable viral load few months prior to admission. He had no history of opportunistic infections and was on HAART therapy at the time of his admission. He presented with a one year history of cough which increased in intensity over the preceding two weeks after travelling to Texas. In addition to a worsening cough, he also complained of a 4-day history of intermittent fevers (temperature of $101-102^{\circ} \mathrm{F}$ ), chills, diaphoresis and diarrhea for 2 days accompanied by abdominal distention and pain. He denied any sputum production, hemoptysis, wheezing, rhinorrhea, or sick contacts. He had an extensive travel history 
to South America and Africa within the last year. His medications included Efavirenz/Emtricitabine/Tenofovir 1 tab daily (started year and a half ago), bupropion 100mg three times a day and escitalopram $10 \mathrm{mg}$ daily. He denied any tobacco use, illicit drug use or alcohol abuse. On physical examination his vital signs were significant for a temperature of $102.7^{\circ} \mathrm{F}$, blood pressure of $96 / 61 \mathrm{~mm} / \mathrm{Hg}$, pulse of $107 / \mathrm{min}$ and a respiratory rate of 20 . He was in no acute distress, awake, alert and oriented to person, place and time. He had a persistent dry cough throughout the exam. He had dry mucous membranes, and his cardiac examination revealed an S1/S2 with no murmurs. His lungs were clear to auscultation, and abdomen was soft, distended, and non-tender to palpationwith a palpable liver edge; bowel sounds were present. Neurological exam was unremarkable. Initial laboratory studies showed a thrombocytopenia of $55 \times 10^{3} / \mathrm{microL}$, and LDH of 1267 U/L. He was admitted to the hospital. Empirical treatment for Pneumocystis jirovecci pneumonia (PJP) was started with Trimethoprim-Sulfametoxazol. His high grade fever persisted $\left(103^{\circ} \mathrm{F}\right)$. A CT scan of the chest, abdomen and pelvis revealed diffuse lymphadenopathy with lymph nodes ranging in size from 1.6 to $4 \mathrm{~cm}$ and hepatosplenomegaly. On day three of admission, he remained febrile, with worsening thrombocytopenia of $42 \times 10^{3} / \mathrm{microL}$, a white blood cell count of $3.84 \times 10^{3} /$ $\mu \mathrm{L}$ and a mild normocytic anemia with hemoglobin of 12.3 $\mathrm{g} / \mathrm{dl}$ and a hematocrit of $34.5 \%$. On day 4 of his admission, he underwent an excisional biopsy of right inguinal lymph node and liver biopsy.

The lymph nodes measured in aggregate $7 \times 4 \times 3 \mathrm{~cm}$. It had a glistening tan lobulated cut surface. Histological examination of the lymph node revealed an almost completely effaced lymph node architecture replaced by diffuse atypical lymphoid proliferation. The lymphoid proliferation consisted of small lymphocytes with a large number of medium-to-large cells with features of immunoblasts-like and Reed-Sternberg-like cells (Figure 1). The atypical lymphoid proliferation was positive for CD20, CD30, MUM-1 and EBV by in situ hybridization (Figure 2) while negative for CD10, BCL-2, CD15, CD138, and T-cell markers. Serum EBV DNA was measured at 2,281,645 copies $/ \mathrm{mL}$. The diagnosis of EBV-positive diffuse large B cell lymphoma was made. In addition to atypical lymphoid proliferation, prominent hemophagocytosis with abundant histiocytes engulfing erythrocytes, lymphocytes and neutrophils was also noted (Figure 3). Further laboratory studies revealed high levels of ferritin $>40,000 \mathrm{ng} / \mathrm{ml}$, triglycerides $>1158 \mathrm{mg} / \mathrm{dL}$, low fibrinogen $139 \mathrm{mg} / \mathrm{dL}$ and low sodium. The clinical and laboratory data supported the diagnosis of HLH established by the Histiocyte Society (Table 1) [3]. The proposed HLH diagnostic criteria by Filipovich were also fulfilled (Table 2) [4].

On day 5 of his admission, he became hypotensive, tachycardic and unresponsive to fluid resuscitation efforts, started on levophed and transferred to the intensive care unit. He was intubated when severe acidosis was shown in arterial blood gas. He was started on continuous veno-venohemofiltration dialysis (CVVHD) for acute kidney failure with a creatinine of $2.96 \mathrm{mg} / \mathrm{dL}$. Pertinent laboratory findings included a CD4 count of 426 , and undetectable viral load. All other tests such as CMV, legionella antigen, mycoplasma pneumonia lg $\mathrm{G}$ and IgM, RPR and hepatitis panel were negative. He was started on decadron and was treated for multi-organ system failure. On day 7 , he was started on intravenous immune globulin (IVIG), Rituximab, Etoposide, Doxorubicin, Vincristine, Prednisone, and Cyclophosphamide (REPOCH). He was started on meropenem for pseudomonal sepsis, micafungin for fungemia and neupogen for neutropenia. His kidney function

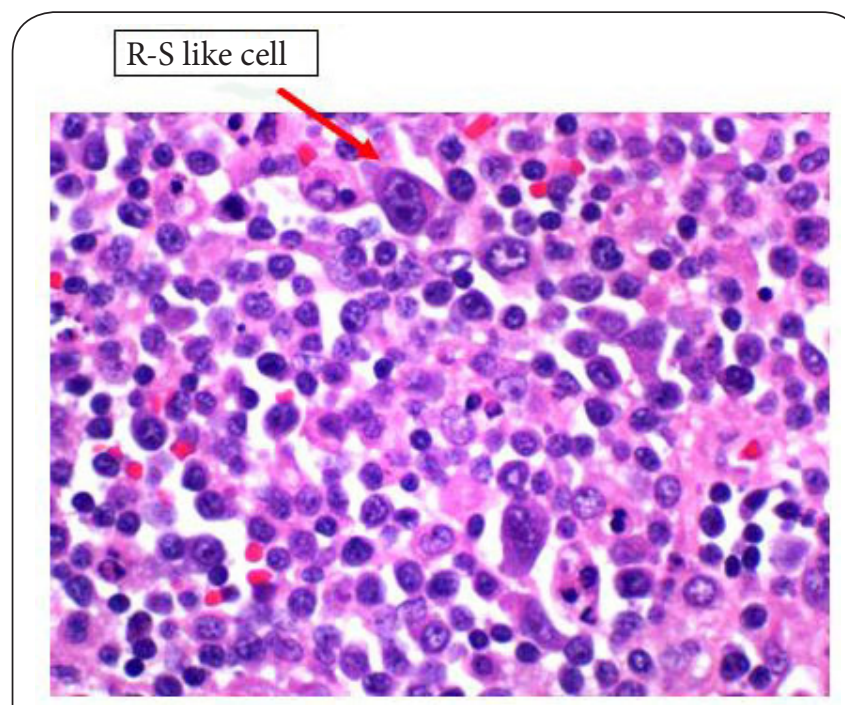

Figure 1. Right inguinal lymph node, 40x. Lymph node with small lymphocytes, large number of medium-to-large cells with features of immunoblasts-like and Reed-Sternberg-like cells (red arrow).

Table 1. Diagnostic criteria for hemophagocytic lymphohistiocytosis.
1. Familial disease/known genetic defect
2. Clinical and laboratory criteria (5/8 criteria)
- Fever
- Splenomegaly
- Cytopenia $\geq 2$ cell lines
- Hemoglobin $<90$ g/L (below 4 weeks $<120$ g/L)
- Neutrophils $<1 \times 109 / \mathrm{L}$
- Hypertriglyceridemia and/or hypofibrinogenemia
- Fasting triglycerides $\geq 3 \mathrm{mmol} / \mathrm{L}$
- Fibrinogen $<1.5 \mathrm{~g} / \mathrm{L}$
- Ferritin $\geq 500 \mu \mathrm{g} / \mathrm{L}$
- $\mathrm{sCD} 25 \geq 2,400 \mathrm{U} / \mathrm{mL}$
- Decreased or absent NK cell activity
- Hemophagocytosis in bone marrow, CSF, or lymph nodes 

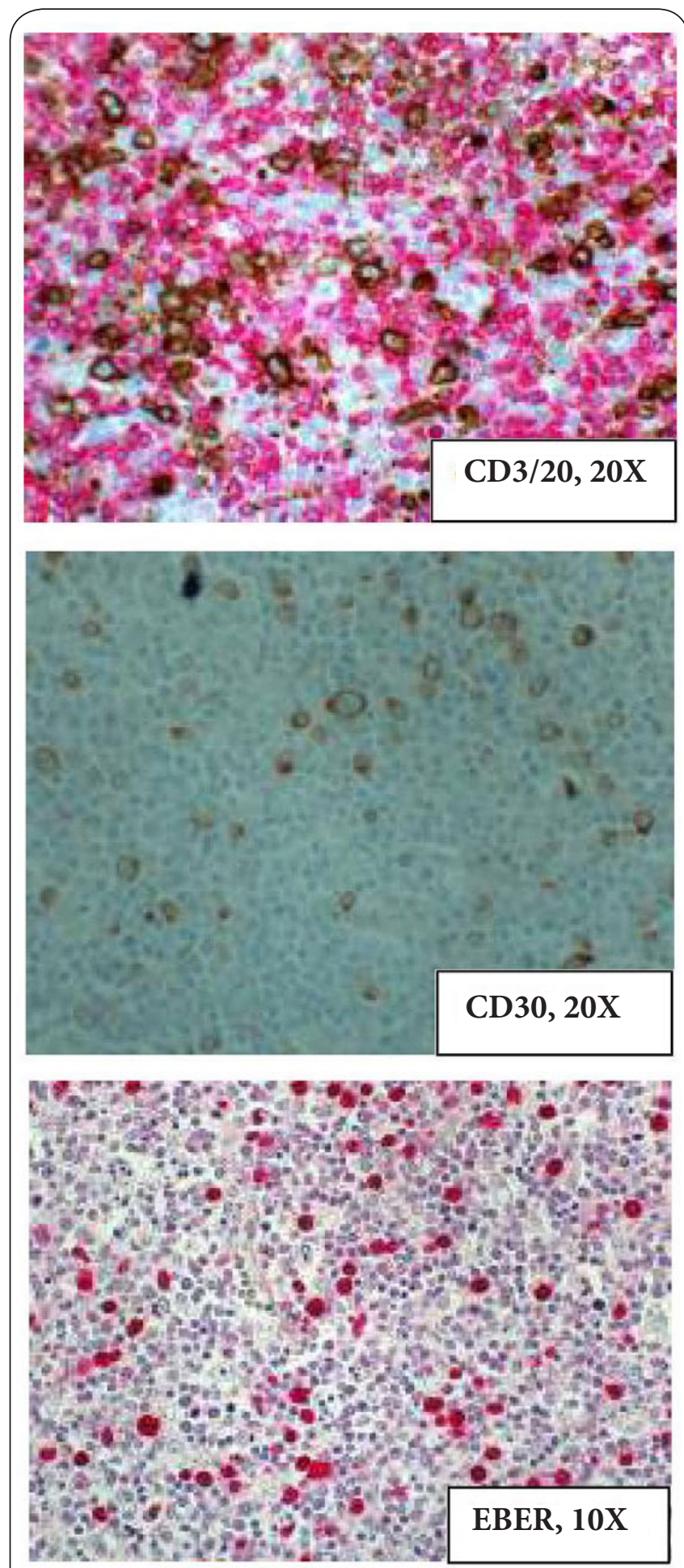

Figure 2. By immunohistochemistry atypical lymphoid cells were positive for CD3 (red) and CD 20 (brown), CD30 and EBER by in-situ hybridization (ISH).

was stabilized and he was taken off CVVHD, transitioned to hemodialysis and finally taken off dialysis and transferred out of the ICU after successful extubation. He was transferred to

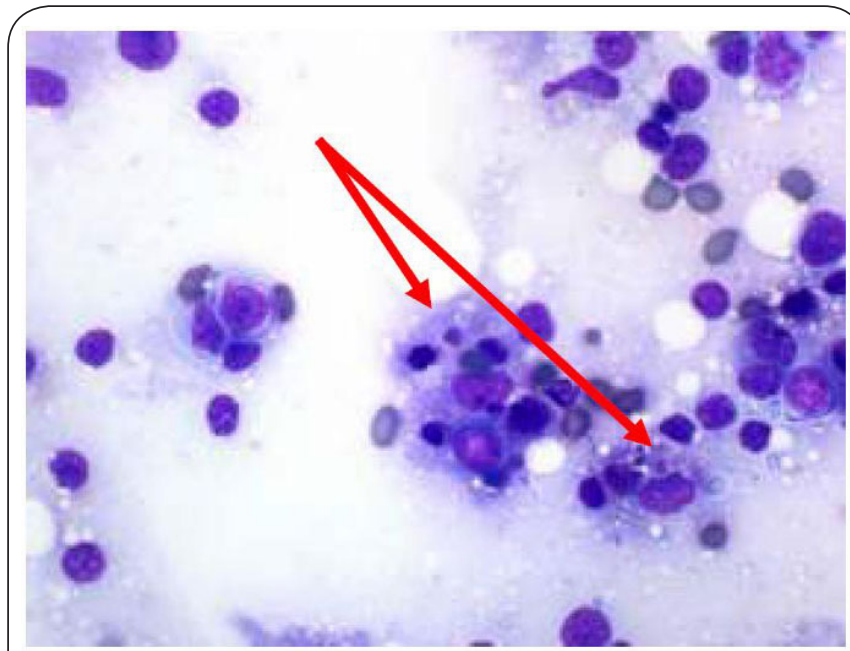

Figure 3. Touch Prep, 60x. Prominent hemophagocytosis with histiocytes engulfing erythrocytes, lymphocytes and neutrophils (red arrows).

Table 2. Proposed HLH diagnostic criteria, 2009.

\begin{tabular}{|c|c|}
\hline $\begin{array}{l}\text { 1. Molecular diagnosis of hemophagocytic } \\
\text { lymphohistiocytosis (HLH) or X-linked } \\
\text { lymphoproliferative syndrome (XLP) }\end{array}$ & - \\
\hline \multicolumn{2}{|l|}{ 2. Or at least 3 of 4 : } \\
\hline a. Fever & + \\
\hline b. Splenomegaly & + \\
\hline c. Cytopenias (minimum 2 cell lines reduced) & + \\
\hline d. Hepatitis & - \\
\hline \multicolumn{2}{|l|}{ 3. And at least 1 of 4 : } \\
\hline a. Hemophagocytosis & + \\
\hline b. $\uparrow$ Ferritin & + \\
\hline c. $\uparrow$ sIL2Ra (age based) & -- \\
\hline d. Absent or very decreased NK function & -- \\
\hline \multicolumn{2}{|l|}{ 4. Other results supportive of HLH diagnosis: } \\
\hline a. Hypertriglyceridemia & + \\
\hline b. Hypofibrinogenemia & + \\
\hline c. Hyponatremia & + \\
\hline
\end{tabular}

rehabilitation unit after approximately one month stay in the hospital and discharged home shortly after. As an outpatient he continued to receive chemotherapy with REPOCH and he was regularly monitored at the Comprehensive Cancer Center. In June 2013, he underwent an allogeneic homozygous CCR5bone marrow transplant at National Institute of Health (NIH) and is currently in remission. His HIV status is continuously being monitored.

\section{Discussion}

$\mathrm{HLH}$ is a rare and potentially life-threatening condition characterized by fever, cytopenias, hepatosplenomegaly 
and hemophagocytosis. It is caused by hyperactivation of the inflammatory system. The cytotoxic T lymphocytes/NK cells cannot induce apoptosis of the target cells; however, they continue to be activated by inflammatory cytokines leading to activation of histiocytes with the consequence of hemophagocytosis, resulting in cytopenia and nonspecific clinical symptoms [5].

$\mathrm{HLH}$ is divided into primary and secondary forms. The primary or familial HLH is commonly found in ethnic groups where consanguineous marriages are common [6]. About 70 $\%$ of the patients develop familial lymphohistiocytosis during the first year of life [3].

The secondary form or reactive HLH occurs in both adults and children and is associated commonly with a variety of underlying disorders including infections, autoimmune conditions and neoplasia. HLH associated with viral infection was first described by Risdall et al., in 1979 [7]. HLH has been reported in all stages of HIV infection and can be the initial presentation of HIV. Niedt et al., reported that $20 \%$ of patients with AIDS had histological hemophagocytosis at autopsy. Thus high level of suspicion of HLH in HIV patient is required in order to make the diagnosis since some of the presenting symptoms can be overlapping [8]. However, the diagnosis of $\mathrm{HLH}$ relies on the criteria set forth by the Histiocyte Society and those criteria must be met in order to diagnose HLH.

Another virus associated with HLH development is EpsteinBarr virus (EBV). EBV infection in humans is usually associated with infectious mononucleosis when patients are exposed to $E B V$ for the first time. EBV normally infects $B$ lymphocytes and epithelial cells. EBV enters the cell via viral glycoprotein gp350 that binds to CD21. Interaction of viral gp42 with MHC class II molecules causes fusion of the viral envelop and allows the virus to enter the cell [10]. Development of HLH is attributed to the abnormal production of cytokines. High levels of interferon- $\lambda$, tumor necrosis factor- $a$, interleukin- 1 , 6 and soluble interleukin- 2 produced by T cells have been demonstrated in HLH [11]. Although T cells lack CD21 receptor for the EBV entrance into the cells, EBV genome was present in $T$ cell lymphomas and $T$ lymphocytes from patients with $\mathrm{HLH}[12,13]$. EBV driven T cell and NK- cell lymphomas are among the most common lymphoid neoplasms associated with the development of HLH [14]. On the other hand, B cell lymphomas are rarely associated with HLH development. $\mathrm{HLH}$ and B cell lymphomas are predominantly described in Asian population and may be related to environmental or genetic factors [15]. Our patient was positive for EBV by in situ hybridization (ISH), and had very high EBV viral copies in the serum. In addition to HIV infection, our patient had EBV reactivation and EBV driven lymphoma that most likely contributed to the development of HLH.

Our report highlights a unique case of a well controlled HIV positive patient who developed EBV driven diffuse large B cell lymphoma complicated by HLH. HIV virus has been described to induce HLH at different stages. EBV virus is also known to produce HLH and lymphomas can be a triggering factor in the development of HLH. Our patient had all three factors that facilitated the development of HLH. The patient was treated aggressively with immunosuppression in addition to chemotherapy and survived $\mathrm{HLH}$, which usually has a poor outcome with mortality rates ranging from $15-60 \%$ [16]. The patient underwent allogeneic homozygous CCR5-transplant with a possibility of curing his large B cell lymphoma and HIV. He is currently under surveillance for his HIV status and lymphoma.

\section{Competing interests}

The authors declare that they have no competing interests.

\section{Acknowledgement}

The authors would like to thank Dr. Jaffe and Dr. Pittaluga at National Institute of Health for their assistance in the diagnosis.

\section{Publication history}

Editors: Wei-Hsiung Yang, Mercer University School of Medicine, USA. Jianxun Song, Penn State University College of Medicine, USA.

Received: 13-Jun-2014 Revised: 30-Jul-2014

Accepted: 02-Sep-2014 Published: 17-Sep-2014

\section{References}

1. Scott RB and Robb-Smith AHT. Histiocytic medullary reticulosis. Lancet. 1939; 2:194-8.

2. Janka G. Hemophagocytic lymphohistiocytosis: when the immune system runs amok. Klin Padiatr. 2009; 221:278-85. | Article | PubMed

3. Janka $G$ and zur Stadt U. Familial and acquired hemophagocytic Iymphohistiocytosis. Hematology Am Soc Hematol Educ Program. 2005; 82-8. | Article | PubMed

4. Filipovich $\mathrm{AH}$. Hemophagocytic lymphohistiocytosis (HLH) and related disorders. Hematology Am Soc Hematol Educ Program. 2009; 127-31. | Article I PubMed

5. Vrotsos E, Soaita M, Khatib Z, Brathwaite C, Filipovich A, Robinson MJ and Castellano-Sanchez A. Atypical clinical presentation of primary hemophagocytic lymphohistiocytosis with a novel perforin 1 gene mutation. J Hematopathology. 2013; 6:105-108.

6. Gurgey A, Gogus S, Ozyurek E, Aslan D, Gumruk F, Cetin M, Yuce A, Ceyhan M, Secmeer G, Yetgin S and Hicsonmez G. Primary hemophagocytic lymphohistiocytosis in Turkish children. Pediatr Hematol Oncol. 2003; 20:367-71. I PubMed

7. Risdall RJ, McKenna RW, Nesbit ME, Krivit W, Balfour HH, Jr., Simmons RL and Brunning RD. Virus-associated hemophagocytic syndrome: a benign histiocytic proliferation distinct from malignant histiocytosis. Cancer. 1979; 44:993-1002. | PubMed

8. Niedt GW and Schinella RA. Acquired immunodeficiency syndrome. Clinicopathologic study of $\mathbf{5 6}$ autopsies. Arch Pathol Lab Med. 1985; 109:727-34. | PubMed

9. Bhatia S, Bauer F and Bilgrami SA. Candidiasis-associated hemophagocytic lymphohistiocytosis in a patient infected with human immunodeficiency virus. Clin Infect Dis. 2003; 37:e161-6. | Article | PubMed

10. Calderwood MA, Venkatesan K, Xing L, Chase MR, Vazquez A, Holthaus AM, Ewence AE, Li N, Hirozane-Kishikawa T, Hill DE, Vidal M, Kieff E and Johannsen $E$. Epstein-Barr virus and virus human protein interaction maps. Proc Natl Acad Sci U S A. 2007; 104:7606-11. I Article I PubMed Abstract | PubMed FullText

11. Fisman DN. Hemophagocytic syndromes and infection. Emerg Infect Dis. 2000; 6:601-8. | Article | PubMed Abstract | PubMed FullText 
Vrotsos et al. Journal of Cancer Therapeutics \& Research 2014, http://www.hoajonline.com/journals/pdf/2049-7962-3-7.pdf

12. Su IJ, Hsu YH, Lin MT, Cheng AL, Wang CH and Weiss LM. Epstein-Barr virus-containing T-cell lymphoma presents with hemophagocytic syndrome mimicking malignant histiocytosis. Cancer. 1993; 72:2019-27. | PubMed

13. Lay JD, Tsao CJ, Chen JY, Kadin ME and Su IJ. Upregulation of tumor necrosis factor-alpha gene by Epstein-Barr virus and activation of macrophages in Epstein-Barr virus-infected T cells in the pathogenesis of hemophagocytic syndrome. J Clin Invest. 1997; 100:1969-79. | Article | PubMed Abstract | PubMed FullText

14. Hagihara M, Inoue M, Hua J and Iwaki Y. Lymphocyte-depleted Hodgkin lymphoma complicating hemophagocytic lymphohistiocytosis as an initial manifestation: a case report and review of the literature. Intern Med. 2012; 51:3067-72. | Article | PubMed

15. Nakamura S, Murase T and Kinoshita T. Intravascular large B-cell lymphoma: the heterogeneous clinical manifestations of its classical and hemophagocytosis-related forms. Haematologica. 2007; 92:434-6. | Article I PubMed

16. Verbsky JW and Grossman WJ. Hemophagocyticlymphohistiocytosis:dia gnosis, pathophisiology, treatment, and future prospectives. Ann Medd. 2006; 38:20-31.

\section{Citation:}

Vrotsos E, Rego C, Cusnir M, Tuda C and Sriganeshan V. Diffuse large b-cell lymphoma with hemophagocytic syndrome in an HIV+ patient treated with CCR5- bone marrow transplant. J Cancer Ther Res. 2014; 3:7.

http://dx.doi.org/10.7243/2049-7962-3-7 